ORIGINAL ARTICLE

\title{
Symptomatology of Postmenopausal Women Presenting at Punjab Rangers Hospital, Lahore
}

\author{
SHABANA KHOKHAR ${ }^{1}$, SABA ILYAS A. MALIK ${ }^{2}$, HUMAIRA DURRANI ${ }^{3}$, AMBREEN NASIR ${ }^{4}$, HUMA TAHSEEN ${ }^{5}$ \\ ${ }^{1}$ Associate Professor, Department of Obstetrics and Gynae, Punjab Rangers Hospital, Lahore \\ ${ }^{2,3}$ Assistant Professor, Department of Obstetrics and Gynae, Punjab Rangers Hospital, Lahore \\ ${ }^{4}$ Senior Registrar, Department of Obstetrics and Gynae, Punjab Rangers Hospital, Lahore \\ ${ }^{5}$ Associate Professor, Department of Obstetrics \& Gynaecology, Azra Naheed Medical College, Superior University \\ Correspondence to: Dr. Shabana Khokhar, Email:khokhar.Shabana@gmail.com, Cell: 03213104423
}

\begin{abstract}
Objective: To describe the immediate symptoms of the post menopausal women attending Punjab Rangers Hospital Lahore.

To see the effects of these symptoms on quality of life (QOL).

Study Design: This was a descriptive type of study that was carried out at the Department of Gynecology and Obstetrics at Punjab Rangers Hospital.

Setting: O\&G OPD at Punjab Rangers Teaching Hospital

Sample Size: 100 patients with menopause were studied for symptomatology and these symptoms affect the quality of life.

Sample Collection: Sample collection was done by a non-probability convenient method. Inclusion Criteria: All patients who attended gynae opd at Punjab rangers hospital with:

- Natural menopause

- Above 45 years

- Below 55 years

- With no other Gynecological problems

Exclusion Criteria: All those patients were excluded from the study that had

- Surgical menopause

- Perimenopause

- History of depressive illness

- Women on antidepressant

- Women on HRT

- Below 45 YEARS

Data Collection: The questionnaires based on menopausal rating scale for symptomatology and quality of life were generated to see the impacts of these symptoms on life.

The educated patients filled questionnaires. I filled out questionnaires of illiterate patients outdoors myself.

Data Analysis: An analysis of data was done by using computer software SPSS.

Data master sheet was developed.

Frequency tables and graphs were generated The data was analyzed by using computer software SPSS.

Confidence interval was calculated for important frequency tables.

Cross tabulation was done for marital status, parity,literacy,smoking and chi-square was applied as a test of significance. $65 \%$ patients described that their quality of life decreased after menopause especially due to vasomotor and psychological symptoms. 35\% of patients were happy and satisfied after their menopause.Besides menopause there were other stresses of middle life, which made life worse.

Subject: The study was performed during the period November2020 to May 2021.Sample was collected by a non probability convenient method and 100 patients were selected. Data was collected by questionnaire provided to patients attending the outpatient department. Data was analyzed with a computer software system by using SPSS.

Results: The mean age observed was 49 years and frequency distribution of symptoms were:Hot flushes $60 \%$, Night sweats 55\%, Insomnia 50\%,Mood changes 60\%,Anxiety 50\%, Irritability 50\%, Memory loss $30 \%$,Vaginal dryness $10 \%$, Dyspareunia 10\%, Loss of libido $15 \%$,Urethral symptoms $25 \%$,Lethargy and general body aches $75 \% .65 \%$ patients described that their QOL had decreased after menopause. 35\% patients described no effect.

Conclusion: To promote the awareness in women about menopause, HRT and other alternatives which can improve their QOL
\end{abstract}

\section{INTRODUCTION}

The menopause marks the end of the menstrual cycle and declining of physiological fertility. The menopause is conventionally said to have occurred when all menstruation has ceased for 12 months. Although menstruation may become irregular yet the period is scantier for several years preceding the menopause. This is the perimenopause period [a period of changing ovarian function]. ${ }^{1}$

Menopause is an outward manifestation of ovarian failure. Exhaustion of primordial follicles leads to an order 
of magnitude of ten-fold decline in circulating oestradiol to a median of about $50-80$ picomole per liter. A level below that found in many healthy age matched men. If the functions of the oestradiol are just limited to reproduction then there is no problem because fertility after fifty years is desired by very few. Instead some women will feel very relaxed after the end of their monthly problems. But the function of estrogens is also known to range beyond the regulation of ovulation, implantation and adaptation to pregnancy. The estrogens have been accorded a central role in the normal function of vasomotor control, skeletal, CNS, CVS, and immune system. An estrogen deficiency leads to the clinical consequences of ovarian failure. The high level of $\mathrm{FSH}, \mathrm{LH}$ is irrelevant to the production of symptoms.

This estrogen deficiency leads to various symptoms such as night sweats, hot flushes, psychological, urogenital, sexual and long-term sequelae like osteoporosis, cardiovascular problems and Alzheimer's disease. '2Due to these consequences of estrogens deficiency, it may have negative effects on quality of life in some women and may increase the morbidity and mortality secondary to osteoporosis or coronary heart diseases. ${ }^{3}$ Most women live long enough to become postmenopausal. Menopause is not a disease but it can be associated with discomfort and decreased quality of life due to its consequences. ${ }^{4}$ The onset of menopause is an excellent time for a women's primary care physician to assess her overall health and the need for health maintenance measures. The realization of profound changes and impacts of these changes on quality of life due to estrogens deficiency and relatively simple treatment make it imperative for the medical professionals to divert an increasing amount of attention to alleviating both the symptoms and the long-term effects. The menopause is an estrogen deficient state and it is thus logical that estrogen replacement will improve the problems.

Symptoms related to menopause are found in all regions of the world, everywhere. Large proportion of women goes through menopause uneventfully. The evidence does not support that woman in developing countries report fewer symptoms than in industrialized countries. ${ }^{6}$

Much work has been done in this field. New drugs are introduced with fewer side effects and with different routes of administration. Few areas of medicines have such a diversity of therapeutic options. ${ }^{7}$

The data on menopause in Pakistan are scarce and scanty. The present study was undertaken to explore the symptoms complex associated with menopause and impacts of these symptoms on quality of life of women .It is therefore important and justified to provide all medical and psychological measures that may ameliorate the quality of life for all woman expecting a prolonged life.

Frequency of Postmenopausal Syndrome

\begin{tabular}{|l|l|l|}
\hline Status of PMS & Frequency & Percenatge \\
\hline PMS Present & 85 & 85.00 \\
\hline PMS Not Present & 15 & 15.00 \\
\hline Total & 100 & 100.00 \\
\hline $\begin{array}{l}\text { Statiscal analysis: } \\
\text { 95\%C.I for postmenopausal } \\
\text { syndrome=76.14 to } 91.08 \%\end{array}$ & & \\
\hline
\end{tabular}

Frequency of Various Symptoms among the PMS Patients

\begin{tabular}{|l|l|l|l|}
\hline Symptoms & Frequency & Percentage & $\begin{array}{l}\text { Statistical } \\
\text { analysis } \\
95 \% c . i\end{array}$ \\
\hline Hot flushes & 60 & 60.00 & $49.70-69.52$ \\
\hline Night sweats & 55 & 55.00 & $44.75-64.85$ \\
\hline Insomnia & 50 & 50.00 & $39.9-60.09$ \\
\hline Mood changes & 60 & 60.00 & $44.70-69.52$ \\
\hline Anxiety & 50 & 50.00 & $39.90-60.09$ \\
\hline Irritability & 50 & 50.00 & $39.90-60.09$ \\
\hline Memory loss & 30 & 30.00 & $21.45-40.10$ \\
\hline Vaginal dryness & 10 & 10 & $5.16-18.04$ \\
\hline Dyspareunia & 10 & 10.00 & $5.16-18.04$ \\
\hline Loss of libido & 15 & 15.00 & $8.91-23.53$ \\
\hline Urethral symptoms & 25 & 25.00 & $17.12-34.17$ \\
\hline Lethargy & 70 & 70.00 & $59.89-78.54$ \\
\hline
\end{tabular}

Cross tabulations

Association of marital status with the PMS

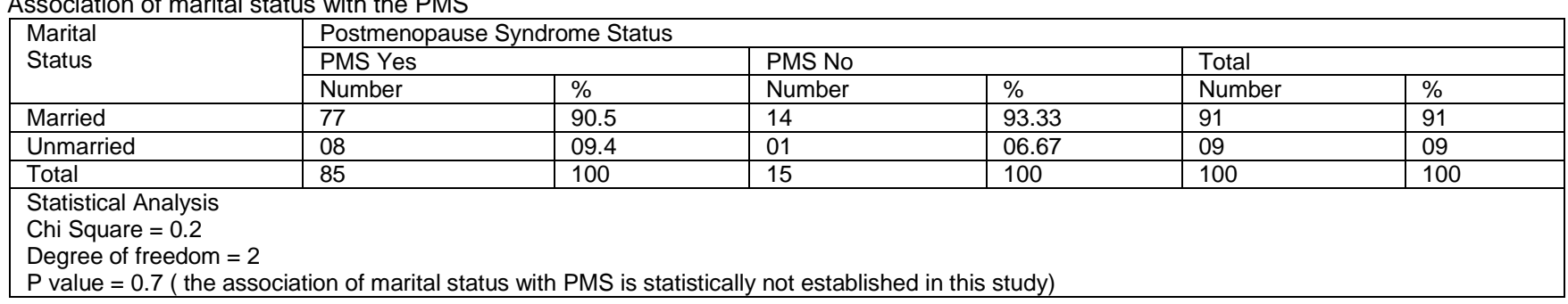

Association of parity status with the PMS

\begin{tabular}{|c|c|c|c|c|c|c|}
\hline \multirow[t]{3}{*}{ Parity Profile } & \multicolumn{6}{|c|}{ Postmenopausal Syndrome Status } \\
\hline & \multicolumn{2}{|c|}{ PMS Yes } & \multicolumn{2}{|l|}{ PMS No } & \multicolumn{2}{|l|}{ Total } \\
\hline & Number & $\%$ & Number & $\%$ & Number & $\%$ \\
\hline Parity 0 & 2 & 2.35 & 0 & 0 & 2 & 2 \\
\hline $1-4$ & 20 & 23.53 & 5 & 33.33 & 25 & 25 \\
\hline 5 and above & 63 & 74.11 & 10 & 66.67 & 73 & 73 \\
\hline Total & 85 & 100 & 15 & 100 & 100 & 100 \\
\hline $\begin{array}{l}\text { Statistical Analysis } \\
\text { Chi Square }=0.94 \\
\text { Degree of freedom }=2 \\
P \text { value }=0.62(\text { the ass }\end{array}$ & n of pa & statisti & ablished & & & \\
\hline
\end{tabular}


Association of smoking with PMS

\begin{tabular}{|l|l|l|l|l|l|l|}
\hline \multirow{2}{*}{ Smoking status } & \multicolumn{4}{l|}{ Postmenopausal Syndrome Status } & Total \\
\cline { 2 - 6 } & PMS Yes & $\%$ & PMS No & Number & $\%$ & Number \\
\cline { 2 - 6 } & Number & 88.61 & 06 & 85.71 & 76 & 10 \\
\hline Non Smokers & 70 & 11.39 & 01 & 14.29 & 86.37 \\
\hline Smokers & 09 & 100 & 07 & & 11.63 \\
\hline Total & 79 & & & \\
\hline Statistical Analysis \\
Chi Square = Not valid \\
$\begin{array}{l}\text { Fisher exact test two tailed P value = 2 } \\
\text { (the association of smoking with PMS is statistically not established in this study) }\end{array}$ \\
\hline
\end{tabular}

Association of Educational status with PMS

\begin{tabular}{|c|c|c|c|c|c|c|}
\hline \multirow[t]{3}{*}{ Educational status } & \multicolumn{6}{|c|}{ Postmenopausal Syndrome Status } \\
\hline & \multicolumn{2}{|c|}{ PMS Yes } & \multicolumn{2}{|l|}{ PMS No } & \multicolumn{2}{|l|}{ Total } \\
\hline & Number & $\%$ & Number & $\%$ & Number & $\%$ \\
\hline Illiterate & 64 & 75.9 & 11 & 73.33 & 75 & 75 \\
\hline Elementary edu & 10 & 11.76 & 3 & 20 & 13 & 13 \\
\hline Matric, F.A & 4 & 4.71 & 6 & 6.67 & 5 & 5 \\
\hline Grad \& above & 7 & 8.24 & 0 & 0 & 7 & 7 \\
\hline Total & 85 & 100 & 15 & 100 & 100 & 100 \\
\hline \multicolumn{7}{|c|}{$\begin{array}{l}\text { Statistical Analysis } \\
\text { Chi Square }=2.01 \\
\text { Degree of freedom }=3 \\
P \text { value }=0.0571 \text { ( the association of literacy with PMS is statistically not established in this study) }\end{array}$} \\
\hline
\end{tabular}

Effects of Pms on Quality of Life

\begin{tabular}{|l|l|l|}
\hline QOL & Frequency & Percentage \\
\hline Affected & 65 & $65 \%$ \\
\hline Not-affected & 35 & $35 \%$ \\
\hline Total & 100 & 100 \\
\hline
\end{tabular}

\section{DISCUSSION}

This study investigated the prevalence of postmenopausal symptoms and health associated quality of life in a women of age range of above 45 years upto 55 year. ${ }^{8}$ In our study the results has revealed, the most of the psychological and vasomotor symptoms and one third of women were happy and satisfied after their menopause. ${ }^{9}$ In most of the Asian populations same results have been observed.My studies findings, showed incidence of hot flushes and night sweats (60\% and $55 \%$ respectively) and lethargy is upto $70 \%$,later finding interestingly correlates with the findings of study by Aida AIDughaither in King Saud Bin Abdul-Aziz University for Health Sciences in March 2015, ${ }^{10}$ their study has also revealed fatigue and stress up to $67.1 \%$. They reported $80.1 \%$ of women had suffered joint and muscular discomfort as the most prevalent symptom postmenopausally.

A study conducted in Thailand showed a higher rate of: vasomotor symptoms $72 \%$, psychological symptoms $93 \%$, urological symptoms $80.7 \%$,these findings are consistent with our study results. ${ }^{11}$ Ceylan B, Özerdoğan From turkey showed that menopausal women suffered from hot flushes $73.9 \%$, generalised aches and pains and joint pains $89 \% .{ }^{12}$ In Japanese the prevalence of the vasomotor symptoms was lowest(18), while increased prevalence of vasomotor symptoms among chinese, caucasian, Hispanic and African American (21\%,31\%,35\% AND $46 \%$ RESPECTIVELY). Moreover, it has been hypothesized that diet plays a very essential role in the severity of menopausal symptoms. ${ }^{13}$ Diets rich in phytoestrogens were found to protect against vasomotor symptoms. The soya products are a rich source of phytoestrogens. ${ }^{14} \mathrm{~A}$ Japanese diet contains high amounts of soya, and this has led to the conclusion that soya may be associated with a decrease in vasomotor symptoms. So a study by Nagata et al provided evidence leading to this conclusion. ${ }^{15} \mathrm{In}$ this study $65 \%$ patients described decreased quality of life, which correlates with the report of Barati M, Akbari-Heidari $\mathrm{H}^{16}$

Local study in Pakistan by Nisar N, Sohoo NA, also showed higher frequency of somatic and psychological symptoms, these are very similar to our study. It was a hospital based cross sectional survey conducted at the department of Obstetrics and Gynecology Isra University Hyderabad Sindh Pakistan from November 2007 to August 2008. ${ }^{17}$ Most prevalent symptom within study subjects was body ache $165(81.7 \%)$ as was observed in our study. Frequencies of some symptoms were $(66.3 \%)$ reported hot flushes $(68.8 \%)$ and $(66.3 \%)$ reported lack of energy and decrease in physical strengths respectively. ${ }^{18}$

Our study revealed that education level also affects the PMS illiterate who had suffered more symptoms $75 \%$ as compared to graduation and above showed $8.24 \%$. Indicators of socioeconomic status also includes level of education and it may affect the lifestyle and reproductive health of women. However, it may also be that women with higher education simply better cope with their VMS. ${ }^{19}$

Other factors which were investigated in our study were,smoking,gravidity,parity, and menarche all of these factors are associated with onset of PMS as compared to study by Lingyan Zhang in China in 2020,that showed no association between post menopausal symptoms and smoking ,level of education and parity. ${ }^{20}$

The diversity in symptoms may be due to better education and awareness and low parity in other countries than Pakistan.

Although parity and educational status is not very significantly associated with PMS in our study. It may be due to the small sample size. 
In future it is recommended that larger sample size and different geographic locations must be included in data collection regarding menopausal symptoms and quality of life during menopausal transition. Our selection of women in study may not represent the whole female population in Pakistan,since it was carried out in a health facility that serves only Punjab Rangers soldiers and their dependents. Most of the females in this sample had low levels of literacy, similar levels of physical activity, and were nonsmokers. In addition, some information taken during patients' interviews might be subjected to recall bias, which might affect median age at onset of menopause.

\section{REFERENCES}

1. World health organization. Research on Menopause in the 1990s: Report of WHO Scientific Group. WHO technical report series 866 . Geneva world health organization;1996.

2. WHITE HEADS -M-I: Menopause: D. Keith Admonts : Dew Hursts Text Books of Obstetrics and Gynaecology , $6^{\text {Th }}$ Edition : Bodmin Cornwell , 1999 ,page 441

3. Tellier-P:Godeau-P: Menopause And Hormone Replacement Rev-Med Interne:2000 May;21[5]:Pages 445-457

4. Palacios-S: Current Perspectives On The Benefits Of HRT In Menopausal Women: Maturitas:1999 November;33 Supplement 11:S1:13

5. Thackers-H-L:Menopause.Prim.Care.1997 March;24[1]:20521

6. EDWARD Morris Gennis Rymer,Updates on the risk benefit ratio of HRT in the menopause,Johan Bonnar,Recent Advances in obstetrics and Gynaecology:Volume 21, London Harcourt Publishers, Edition 2001,Page 161

7. Obermeyer-CM Menopause across cultures. Menopause.2000 May -June [3];184-92

8. Custom TM:Meulaman-E.Managing Menopause.AM.fam.Physician.2000 March 1;61[5]:1392$9,1405-6$
9. Davey D.A: The Menopause and Climacteric,Charles R.Whitfield:Dew HURST'S textbooks of Obstetrics and Gynaecology: $5^{\text {th }}$ Edition:Bath Black Well Series,1995,Page number 605

10. AAida Aldughaither:Menopausal symptoms and quality of life among Saudi women visiting primary care clinics in Riyadh,Saudi Arabia;29 june 2015 Volume 2015:7 Pages 645-653

11. Pasini-W,Menopause and quality of life;Med-Prax 1997 August 13;86[33]1264-7

12. Brad-R-J: The Menopause.British Journal Of Medicine: 1957,Vol.13,631-7

13. Yahya S ; Rehan N. Age pattern and symptoms of menopause among rural women of Lahore. J Ayub Med. Coll. Abbottabad : 2002;14[3]:9-10

14. Peeyananjarassri K, Cheewadhanaraks S, Hubbard M, Zoa Manga R, Manocha R, Eden J.Climacteric. 2006 Feb;9(1):23-9.

15. Ceylan B, Özerdoğan N.Climacteric. 2014 Dec;17(6):705 12.Epub 2014 Aug 17. PMID: 24884351

16. Barati $M$, Akbari-Heidari $H$, Samadi-Yaghin $E$, Jenabi $E$, Jormand H, Kamyar N.BMC Women's Health. 2021 May 18;21(1):208.

17. Aarone R.Muliyil J; Medico-social dimensions of menopause; National Med. India:2002; January/February 15[1], 14-17

18. Nagata C, Takatsuka N, Kawakami N, Shimizu H. Soy product intake and hot flashes in Japanese women: results from a community - based prospective study. $A m \mathrm{~J}$ Epidemiol. 2001;153(8):790-793.

19. Nisar N, Sohoo NA. Severity of menopausal symptoms and quality of life at different status of menopause: a community based survey from rural sindah, Pakistan. Int $J$ Collab Res Intern Med Public Health. 2010;2(5):118-130.

20. Gold EB, Block G, Crawford S, et al. Lifestyle and demographic factors in relation to vasomotor symptoms: baseline results from the study of women's health across the nation. Am J Epidemiol. 2004;159:1189-1199. 